\title{
O brincar no espaço escolar como estratégia de inclusão de alunos com Transtorno
}

\section{do Espectro Autista (TEA)}

\author{
Playing in the school space as a strategy for the inclusion of students with Autistic Spectrum \\ Disorder (ASD) \\ Jugar en el espacio escolar como estrategia para la inclusión de estudiantes con Trastorno del \\ Espectro Autista (TEA)
}

Recebido: 09/05/2021 | Revisado: 18/05/2021 | Aceito: 21/05/2021 | Publicado: 08/06/2021

\author{
Antônio Eustáquio de Oliveira Fam \\ ORCID: https://orcid.org/0000-0001-6135-7415 \\ Instituto Federal de Educação, Ciência e Tecnologia de Minas Gerais, Brasil \\ E-mail: antonio.eustaquio.fam@gmail.com \\ Sérgio Pereira dos Reis \\ ORCID: https://orcid.org/0000-0003-0209-4314 \\ Instituto Federal de Educação, Ciência e Tecnologia de Minas Gerais, Brasil \\ E-mail: sergiousreis@gmail.com \\ Rosemery Pereira Costa e Barbosa \\ ORCID: https://orcid.org/0000-0001-5368-2162 \\ Instituto Federal de Educação, Ciência e Tecnologia de Minas Gerais, Brasil \\ E-mail: rose.costa@ifmg.edu.br
}

\begin{abstract}
Resumo
O presente artigo objetivou compreender se o brincar favorece a inclusão de alunos diagnosticados com Transtorno do Espectro Autista (TEA) e se pode ser utilizado como uma estratégia para a inclusão escolar. Para elucidar a questão foi desenvolvido um estudo de caso de cunho qualitativo e descritivo com os profissionais de educação de uma escola pública do município de Governador Valadares, Minas Gerais. Utilizou-se como instrumento de pesquisa o questionário aplicado via formulário Google Forms. Conforme os dados obtidos observou-se que na percepção dos respondentes o brincar favorece na inclusão de alunos diagnosticados com TEA e pode ser utilizado como uma estratégia para esta inclusão, principalmente por propiciar o desenvolvimento global das crianças, uma vez que, na visão dos mesmos propicia aprendizagem, interação e respeito a diferença. Os respondentes apontaram ainda a importância do estreitamento da relação família-escola para o trabalho mais efetivo com as crianças e a necessidade de formação continuada para sustentar o trabalho de inclusão. O trabalho evidencia como o brincar está cada vez mais presente nas escolas e sua importância na inclusão e na autonomia dos alunos.
\end{abstract}

Palavras-chave: Inclusão escolar; Transtorno autístico; Brincar; Crianças; Escola.

\begin{abstract}
This article aimed to understand whether playing favors the inclusion of students diagnosed with Autistic Spectrum Disorder (ASD) and whether it can be used as a strategy for school inclusion. To elucidate the issue, a qualitative and descriptive case study was developed with education professionals from a public school in the city of Governador Valadares, Minas Gerais. The questionnaire applied via the Google Forms was used as a research tool. According to the data obtained, it was observed that in the respondents' perception, playing favors the inclusion of students diagnosed with ASD and can be used as a strategy for this inclusion, mainly because it promotes the global development of children, since, in their view provides learning, interaction and respect for difference. Respondents also pointed out the importance of strengthening the family-school relationship for more effective work with children and the need for continued formation to support inclusion work. The work shows how playing is increasingly present in schools and its importance in the inclusion and autonomy of students.
\end{abstract}

Keywords: School inclusion; Autistic disorder; To play; Kids; School.

\section{Resumen}

Este artículo tuvo como objetivo comprender si el juego favorece la inclusión de estudiantes diagnosticados con Trastorno del Espectro Autista (TEA) y si se puede utilizar como estrategia de inclusión escolar. Para dilucidar el tema, se desarrolló un estudio de caso cualitativo y descriptivo con profesionales de la educación de una escuela pública de la ciudad de Governador Valadares, Minas Gerais. Se utilizó el cuestionario aplicado a través del formulario Google Forms como herramienta de investigación. De acuerdo con los datos obtenidos, se observó que en la percepción de los encuestados, el juego favorece la inclusión de estudiantes diagnosticados con TEA y puede ser utilizado como una 
estrategia para esta inclusión, principalmente porque promueve el desarrollo global de los niños, ya que, en su la vista proporciona aprendizaje, interacción y respeto por la diferencia. Los encuestados también señalaron la importancia de fortalecer la relación familia-escuela para un trabajo más eficaz con los niños y la necesidad de una formación continua para apoyar el trabajo de inclusión. El trabajo muestra cómo el juego está cada vez más presente en las escuelas y su importancia en la inclusión y autonomía de los estudiantes.

Palabras clave: Inclusión escolar; Trastorno autista; Jugar; Niños; Colegio.

\section{Introdução}

Nada é tão natural e intrínseco quanto o brincar para a criança. O brincar é uma ação de autonomia, espontaneidade e de emoção, onde se pode perceber que as crianças se movimentam em prol da produção de um mundo onde elas podem atuar como sujeitos ativos e com liberdade de ação e expressão. Esse mundo, muitas vezes, cercado por imaginações e espontaneidades distintas se traduz em representações de experiências da criança com o meio, como emoções, felicidade, contradições e perdas singulares (Almeida, 2014). Quando se pensa em uma criança, como sujeito de direitos e sob proteção da família e do Estado, vê- se uma pessoa que se constrói em cada fase, desenvolvendo-se, em todas suas características, para sua participação no mundo, como um sujeito fazedor de sua história (Freire, 2016).

Nesta perspectiva, é pertinente indagar se o brincar pode ser utilizado como uma estratégia de inclusão nas escolas. Essa indagação demonstra a importância do brincar a partir da concepção de que essa atividade tão simples e típica na infância, ao modo de entendimento doxal, pode mudar toda uma trajetória pedagógica, cidadã e, principalmente, humanizadora de um sujeito.

O brincar é uma ação que está arraigada à infância em todos seus aspectos. Não se imagina uma brincadeira onde não é lembrada a figura de uma criança. Toda e qualquer forma de brincar traz consigo uma sensação de liberdade, autonomia e de emoção, criando laços com a imaginação e com as outras pessoas que se interagem na atividade. Conforme aponta Cipriano \& Almeida (2016, p. 79) "o brincar á a principal forma utilizada pela criança para comunicar-se, expressar-se, relacionar-se e aprender". Assim, o brincar é uma atividade que vem ganhando importância científica no que tange as suas contribuições pedagógicas, sem, no entanto, perder sua naturalidade e cunho cultural. Se faz necessário entender que a atividade do brincar é algo cultural, dentro das suas especificidades e de acordo com cada cultura, que traz a criança para um universo de experimentação e do aprendizado de seu grupo social. Neste sentido, percebe-se que o brincar por ser aprendido culturalmente e por isto pertencente a coletividade de um determinado grupo, pode ser uma atividade que contribui em todas diversas dimensões para a efetivação da inclusão de alunos/alunas que necessitam de um atendimento especializado.

A inclusão no sistema educacional é uma conquista historicamente construída, que foi se estabelecendo em dicotomia ao termo exclusão. Mendes (2001) define que inclusão se fundamenta no reconhecimento da diversidade que compõe a sociedade. Rocha (2017) define inclusão como uma inovação que exige a reestruturação e adaptação das escolas às novas exigências do aluno com necessidades educacionais especiais. Ao analisar esses posicionamentos, percebe-se que a inclusão é uma construção através de lutas e conquistas de movimentos sociais, que de forma ativista e engajada lutaram por direitos que não eram reconhecidos por políticas sociais. Neste contexto, o Transtorno do Espectro do Autismo (TEA) deve ser pensado dentro das políticas de inclusão.

O TEA está classificado no DSM-5 como uma categoria pertencente ao quadro dos Transtornos de Neurodesenvolvimento (APA, 2014). Com base nessa classificação e nas políticas públicas nacionais e, também, com grande contribuição, as políticas internacionais de positivação da inclusão, o TEA é trabalhado como uma deficiência que necessita de um acompanhamento especial no âmbito escolar. (Brasil, 2001).

Pensando na possibilidade de uma escola cada dia mais inclusiva para os alunos com TEA, este artigo objetivou compreender se o brincar favorece a inclusão de alunos diagnosticados com Transtorno do Espectro Autista (TEA) e se pode, neste sentido, ser utilizado como uma estratégia para esta inclusão. 


\section{Acerca do Transtorno do Espectro Autista (TEA) e a Inclusão Escolar e o Brincar}

No cenário legislativo nacional, pode se conceber a educação como um direito de todos e todas (Brasil, 1988). Dentro dessa perspectiva, sem a análise minuciosa do dever estatal e da família, várias foram as leis infraconstitucionais que trabalham a educação, em especial a educação para as pessoas com necessidades especiais.

A Declaração de Salamanca documento originado a partir de discussões oriundas da Conferência Mundial sobre a Educação Especial no ano 1994, na cidade espanhola de Salamanca, no qual o Brasil é signatário, trouxe mudanças estruturais no campo do atendimento educacional para pessoas com necessidades especiais (Unesco, 1994). Arruda e Dikson (2018) afirmam que esse documento internacional, de importância inigualável, tem caráter democrático em sua essência no que tange a inclusão, passando a oportunizar as populações com necessidades especiais direitos que durante muitos anos foram ceifados. Os autores ainda salientam que o referido documento corrobora para que as instituições escolares passem a se adequar às especificidades de cada aluno, mudando seus paradigmas, se refazendo socialmente e culturalmente. Dentro da mesma linha, Alencar et al. (2016) reforçam que a Declaração de Salamanca traz um novo cenário para a educação, possibilitando aos alunos com necessidades especiais o acesso às escolas de ensino regular, as quais têm o dever de se adequarem as especificidades de cada aluno.

A Lei de Diretrizes e Bases da Educação Nacional (LDBEN), Lei n ${ }^{\circ}$ 9.394/96, trouxe consigo um montante de mudanças na proposta de educação para todos. Nas linhas que transcrevem o texto legal da LDB, mais especificamente nos artigos 58 e 59 , a lei oportuniza o conceito de educação especial e positiva o acesso de pessoas com necessidades especiais, preferencialmente, em escolas de ensino regular. Segundo a referida lei:

Art. 58 Entende-se por educação especial, para os efeitos desta lei, a modalidade de educação escolar, oferecida preferencialmente na rede regular de ensino, para educandos portadores de necessidades especiais (Brasil, 1996).

Ao definir educação especial, o legislador teve o cuidado de enfatizar que o ensino para os alunos com necessidades especiais deve ser oferecido preferencialmente na rede regular de ensino. Isso demonstra que os documentos foram sendo construídos de forma a promover a inclusão de forma universal, independente se o aluno tenha alguma especificidade ou não. Desta forma, a escola passa ser um ambiente de todos e todas. Isso demonstra que as escolas, com o investimento do poder público, têm o dever de se adaptar a todo e qualquer tipo de aluno que será matriculado. Fam, Reis \& Silva (2020) reforçam essa ideia ao salientar que a função da escola é adaptar-se ao aluno com necessidades educacionais especiais matriculados, invertendo a lógica que antes do movimento da inclusão a criança era obrigada a adaptar-se a rotina da escola para que seja incluída. Mantoan (2004) defende que a inclusão é a consideração das diferenças como um fator universal entendendo seus aspectos e percebendo os desafios diários de luta por isonomia.

O Transtorno do Espectro do Autismo (TEA) também é positivado como deficiência através da lei Berenice Piana, Lei $\mathrm{n}^{\mathrm{o}}$ 12.764/2012, que afirma no $\S 2^{\circ}$ do Artigo $1^{\circ}$ que "a pessoa com transtorno do espectro autista é considerada pessoa com deficiência, para todos os efeitos legais" (Brasil, 2012). Essa definição reafirma, constitucionalmente e legalmente, que a pessoa com TEA considerada deficiente e detentora de todos os direitos e proteções legais e estatais contra qualquer tipo de violação. O TEA é um déficit que a pessoa tem em relação a sua interação em sociedade, tendo muito comprometimento na comunicação e na socialização, podendo ser severa e branda.

Alves e Alves (2016) entendem que as ideias dominantes sobre as pessoas com necessidades especiais se pautaram, e ainda se pautam em pressupostos excludentes. Essa afirmação dos autores baseia-se no fato de que por mais que se aprovem projetos e leis no âmbito político e legislativo, as exclusões são nítidas nos espaços escolares, quando não se concebe um espaço físico adequado para a locomoção dos alunos que necessitam de adaptações para poder, pelo menos, chegar à sala de aula; percebe-se, também, quando são utilizados materiais didáticos e paradidáticos que não atendem às especificidades de alunos 
cegos ou com TEA; ou quando não se tem um intérprete de Libras que possa trazer ao aluno surdo o conteúdo ministrado pelo educador.

Raiça e Machado (2006) enfatizam que a escola tem um desafio para consolidar a inclusão, pois os profissionais da educação, ainda, são despreparados e desinformados para trabalharem com as distintas especificidades de cada aluno matriculado. Santhiago e Colonetti (2017, p. 50) reforçam essa tese ao evidenciar que apesar das mudanças na sociedade, ainda há vestígios do pensamento excludente mascarado, mesmo nos educadores que rejeitam o aluno com necessidade especial. As autoras ilustram que "excluir é afastar determinado indivíduo ou grupo específico do meio em que vive".

No meio acadêmico e escolar é comum a confusão acerca dos termos "inclusão" e "integração". A integração foi uma forma compulsória que as escolas adotaram para o recebimento do aluno que apresentava necessidades educacionais especiais, sendo como marco principal o aluno se adaptar ao andamento e a estrutura das escolas. Miranda (2008) salienta que o termo inclusão deve ser reconhecido e trabalhado em perspectiva diferente do conceito de integração. Segundo a autora, o conceito de inclusão considera o aluno ou a aluna de outro ângulo e visão do que é visto na integração, pois reconhece a existência das inúmeras diversidades na composição da sociedade. Em consonância a essa linha de pensamento, Rocha (2017) reforça que as escolas têm o dever de rever seus currículos, propostas, espaços e seus paradigmas para a inclusão.

Rocha (2017) salienta que a necessidade da formação continuada dos professores para adquirirem concepções destinadas à educação para todos. Segundo o autor "a escola inclusiva depende de adaptações de grande e médio porte" (ROCHA, 2017, p. 4). Além disso o autor traz a seguinte definição para o termo inclusão:

A inclusão nada mais é que um processo de inovação que exige um esforço de reestruturação e atualização de algumas escolas fazendo com que essas escolas busquem uma reorganização escolar ampliando seu projeto político pedagógico, incorporando novas práticas aos currículos e realizem adaptações físicas necessárias (Rocha, 2017, p. 7).

Percebe se que através das discussões elencadas que existe uma grande lacuna entre o que é proposto pelas leis e o que é efetivo nas escolas. Não se culpa, aqui, os gestores e educadores, pois ainda faltam investimentos do poder público na adequação das escolas para a inclusão de todas as diversidades.

\subsection{O brincar na vida e nas escolas}

O brincar é concebido por muitos como uma atividade de "perda de tempo" no que tange no preparo para a vida dentro de uma sociedade capitalista. Isso traz na criança aquela pressão interna e subjetiva de sempre fazer as coisas ou atividades para obter a aprovação do adulto, pois ela se sente pressionada pelos anseios capitalistas e aspiradores da família. Questões como essas que trazem e, diretamente e indiretamente, contribuem para a descaracterização do brincar como uma prática única, simples e necessária no desenvolvimento da criança. Isso é muito preocupante, não porque as crianças não conseguem realizar as tarefas, mas pelo fato da família ceifar um período tão peculiar e construtivo para o ser humano, como é a infância.

Porém, é importante salientar que todos esses argumentos estão vencidos no campo educacional e, também, social, pois o brincar foi positivado, através da Base Nacional Comum Curricular (BNCC) como um dos direitos de aprendizagem e desenvolvimento (Brasil, 2014). Essa inclusão do brincar como um campo de aprendizagem e desenvolvimento reflete que:

A interação durante o brincar caracteriza o cotidiano da infância, trazendo consigo muitas aprendizagens e potenciais para o desenvolvimento integral das crianças. Ao observar as interações e a brincadeira entre as crianças e delas com os adultos, é possível identificar, por exemplo, a expressão dos afetos, a mediação das frustrações, a resolução de conflitos e a regulação das emoções (Brasil, 2014, p. 39). 
Mesmo brincando sozinha a criança tem a capacidade de interagir consigo mesma, com o ambiente e com os brinquedos, sendo desafiadores imediatos nas atividades lúdicas das crianças, estimulando sua autoexpressam (Cunha, 2007). Reforçando essa ideia, Daguano e Fantacini (2011) destacam que:

Através dos jogos, brinquedos e brincadeiras podemos estimular a imaginação, a auto-estima e a cooperação entre as crianças, permitindo, assim que a criança interaja e estabeleça relações sociais com as outras crianças (Daguano \& Fantacini, 2011, p. 110).

É importante saber o valor pedagógico e humanizador do brincar para a criança em processo de desenvolvimento. Ele é quem desperta no aluno algumas especificidades que em muitas outras atividades não são evidenciadas. Damasceno, Leandro e Fantacini (2017) e Teles (1997) defendem que o brincar é uma ferramenta muito importante de exploração do mundo, onde, de forma prazerosa, a criança constrói vínculos, sentimentos e prazeres, ativando sua imaginação e criatividade.

No que tange o brincar nas escolas, percebe-se muitos estudos, como os de Almeida (2014), Alves e Alves (2016), Cipriano e Almeida (2016), Cunha (2007), Daguano e Fantacini (2011), Damasceno, Leandro e Fantacini (2017), Lameirão (2007), Martins \& Alves (2018), Ramos e Ribeiro (2018), Santana et al. (2016), Silva et al. (2013) e Teles (1997), que enaltecem sua utilização para o aprendizado e convívio, tornando-o mais envolvente, lúdico e conciliador com a idade do aluno. A utilização do brincar como estratégia pedagógica é um ganho, tanto para o educador quanto para a criança. A brincadeira é construtora de elos entre a as crianças e, também, entre as crianças e os adultos. Como destaca Daguano e Fantacini (2011) o lúdico torna o ensino mais prazeroso, contribuindo para aquisição de aprendizados, habilidades e aperfeiçoamentos, oriundos dos objetivos de cada atividade.

\subsection{Transtorno do Espectro do Autismo (TEA)}

Quanto a criança com TEA, estudos revelam que o brincar á uma ferramenta determinante na sua construção como ser autônomo e possibilita a interação com as outras pessoas. O TEA tem o aspecto de interferir nas questões da comunicação, imaginação e socialização das pessoas (Daguano \& Fantacini, 2011). No entanto, quando a criança é estimulada, a partir dos seus primeiros anos de vida, essas questões são amainadas, desenvolvendo certas habilidades que não são percebidas pelo fato do autismo prevalecer como preocupação primeira. Essa afirmação é importante pelo fato de as pessoas sempre focarem em aspectos negativos das necessidades especiais, esquecendo que há um ser humano, e que ele necessita ser estimulado e valorizado como detentor de uma potencialidade.

Alguns autores como Fam, Reis e Silva (2020), Favoretto e Lamônica (2014), Santana et al. (2016) e Silva et al. (2013) definem o TEA como um comprometimento que a pessoa pode apresentar na interação social e na comunicação, interferindo na sua vida cotidiana.

Dentro dessas definições o que de fato se vê no interior das escolas? Fam, Reis e Silva (2020) fizeram um estudo referente à inclusão de alunos com TEA nas unidades do Colégio Tiradentes da Polícia Militar de Minas Gerais, e através de uma pesquisa empírica, perceberam que, por mais que haja leis e instruções internas normativas, a inclusão ainda é tratada sob uma perspectiva formal legal, sem a devida adequação. Segundo os autores:

(...) é evidente que o TEA é um tema que ainda requer muita investigação e debate, pois em uma sociedade que em sua essência se mostra plural e diversa, mas materialmente, pelas ações cotidianas, não pluraliza, há grande necessidade de quebra de paradigmas dentro e fora das escolas (Fam, Reis \& Silva, 2020).

Vigotski (1984) em sua tese sobre a defectologia relata que existem duas formas de deficiência, sendo a primária aquela que diz respeito às suas necessidades especiais. Por sua vez, Santana et al. (2016) na adoção do termo "singularidades reais e 
visíveis"; definem a deficiência secundária como sendo aquela denotada pelos empecilhos e preconceitos sociais e culturais. A construção da segregação tem suas artimanhas (Sawaia, 2001), para excluir ainda mais a pessoa marginalizada socialmente; sucumbindo todas as formas de se estabelecer como pessoa possuidora e construtora de sua própria história (Freire, 2016). Isso demonstra que as consequências sociais são mais abrasivas às pessoas que apresentam necessidades especiais, em suas diversas formas, do que a deficiência no seu sentido clínico e orgânico.

O brincar dentro da perspectiva da inclusão de pessoas com TEA em escolas de ensino infantil ganha uma importância por apresentar uma forma lúdica e prazerosa de intervenção. Ela favorece o respeito a autonomia de escolha e de ensino da criança, criando, dentro do universo escolar, uma educação humanizadora, que, além de responder as necessidades educacionais da criança, corresponde como um meio de interação e criação de vínculos entre as crianças e os educadores. Cipriano \& Almeida (2016) destacam que o brincar é a mediação que se apresenta entre o universo subjetivo da criança e o meio em que ela vive. Isso demonstra o quanto o universo infantil é complexo e repleto de singularidades que podem ser trabalhadas e exploradas pelos educadores. Desafios, estes, que segundo Alves e Alves (2016) demandam dos educadores desenvolvimento de estratégias de ensino que favoreçam a inclusão das crianças com TEA nas escolas.

Vale ressaltar que, devido aos déficits de comunicação, interação social e maior adesão a comportamentos repetitivos e falas com ecolalias, para a criança com TEA o brincar se torna disfuncional se não houver intervenção e estimulação. Cipriano e Almeida (2016) destacam o que é o brincar dentro do universo da criança do TEA, ressaltando o quanto essa prática pode ser disfuncional sem a intervenção pedagógica para a devida estimulação conforme cada necessidade. Os autores apontam que:

As crianças que se encontram dentro do TEA podem apresentar comportamento característico de rigidez, repetição de movimentos e escolhas, baixa atividade exploratória (brincar empobrecido), baixo potencial imaginativo nas atividades ligadas ao brincar, com déficit no comportamento social. Esses comportamentos não favorecem uma maior vivência de experiência e da exploração do brincar, visto que se limitam, muitas vezes, a repetições ritualísticas, ao brincar isolado e disfuncional, não permitindo a interferência e participação de outras crianças e/ou adultos nesse momento (Cipriano \& Almeida, 2016, p. 82).

Ramos e Ribeiro (2018) elencam que devido as restrições que o TEA traz para a criança, como a dificuldade de comunicação, interação social e a rigidez de não abarcar novas tarefas e desafios, a forma do seu brincar pode ser afetada. Contudo, segundo os autores, mesmo apresentando alguns déficits no brincar a criança com o autismo tem sua singularidade/especificidade durante a atividade lúdica.

Ramos e Ribeiro (2018) em seu estudo enfatizam a importância do brincar como uma "ação pedagógica" de inclusão, vínculo e aprendizagem, onde, a partir de uma pesquisa empírica em uma escola da cidade de Recife/PE, foram ouvidas professoras e ficou constatado que a atividade lúdica é uma importante ferramenta de quebra de barreiras para alunos que apresentam necessidades educacionais especiais.

A partir desta perspectiva, é importante ter como ação, no campo pedagógico e social, a estimulação dentro das necessidades da criança com TEA, trabalhando a percepção imaginativa, a comunicação, a interação social, a organização, a fala e, principalmente, a sua autonomia. O brincar se mostra como uma ferramenta, lúdica e pedagógica, que pode ser um meio que explora todas as necessidades que a criança com TEA apresenta, tornando sua estimulação atrativa e prazerosa.

\section{Metodologia}

A pesquisa tem como escopo a aproximação e entendimento científico da realidade, como forma de dar respostas as indagações e problemas que são inerentes a realidade social (Gerhardt \& Silveira, 2009). Dentro dessa perspectiva de discutir a inclusão de alunos com TEA no espaço escolar e o brincar como uma estratégia de inclusão destes alunos, buscou-se, através de 
um estudo de caso de cunho qualitativo e caráter descritivo, entender o contexto de uma escola estadual do município de Governador Valadares, Minas Gerais.

Segundo Gerhardt e Silveira (2009) uma das principais características da pesquisa qualitativa é descrever, compreender e explicar com precisão o porquê das coisas, produzindo informações para o amadurecimento científico e pessoal dos pesquisadores. Santhiago e Colonetti (2017) reforçam que o tipo de pesquisa qualitativa não visa dados numéricos ou estatísticos, porém se constrói através da análise e compreensão da relação do sujeito com o fenômeno estudado, aqui nos detemos nas relações dos professores no processo de inclusão dos alunos com TEA.

Dantom (2002) salienta que a pesquisa descritiva tem como objetivo observar, analisar e registrar fenômenos oriundos do objeto pesquisado, sem manipulá-los. A pesquisa tem como escopo um estudo de caso realizado em uma escola pública do Município de Governador Valadares, no Estado de Minas Gerais, que objetivou compreender se o brincar favorece a inclusão de alunos diagnosticados com TEA e se pode ser utilizado como uma estratégia para esta inclusão. Reforçando o pensamento de Dantom (2002), Gil (2002, p. 54) relata que o estudo de caso é um "estudo profundo e exaustivo de um ou poucos objetos, de maneira que permita seu amplo e detalhado conhecimento, tarefa praticamente impossível mediante outros delineamentos já considerados". Com isso, um dos objetivos do estudo de caso é explorar situações da vida real, onde as vivências e ações do diaa-dia são peças de problematização do pesquisador.

Para atender aos objetivos da pesquisa utilizou-se como instrumento de pesquisa o questionário. Para Gil (2002), o questionário é uma peça de coleta de dados que utiliza como ferramenta a interrogação. Segundo o autor, o questionário constitui um meio mais rápido e barato, que não necessita de treinamento prévio pessoal para ser desenvolvido. O questionário teve como composição 20 questões, sendo 17 objetivas e 03 dissertativas, as quais foram divididas em três partes: 1) o perfil do funcionário e sua formação acadêmica; 2) o aspecto da inclusão e suas implicações legais, e 3) a análise do brincar no ambiente escolar como estratégia de inclusão dos alunos com TEA.

Os sujeitos de pesquisa foram os supervisores, a diretora, professores regentes, professores de atendimento educacional especializado, bibliotecário e pedagogos, sendo ao todo 32 profissionais da escola em questão. Obteve-se a participação de $87 \%$ de adesão a pesquisa (28 profissionais).

Para efetivar a coleta de dados, o questionário foi disponibilizado no e-mail oficial da escola pesquisada e ficou disponível no período de 01 a 15 de agosto de 2020. Foi frisado no Termo de Consentimento Livre e Esclarecido a não obrigatoriedade de participação dos envolvidos da pesquisa e o caráter voluntário do mesmo

A análise dos questionários respondidos se deu observando os gráficos produzidos pelo Google Forms e análise das respostas das questões dissertativas. Para esta análise, numerou-se aleatoriamente os questionários e buscou-se em cada questão construir categorias de acordo com as similaridades das respostas. Após a criação destas categorias, as diferentes categorias foram analisadas de acordo com as teorias estudadas.

\section{Resultados e Discussão}

O objetivo principal da pesquisa é compreender se o brincar favorece a inclusão de alunos diagnosticados com TEA e se pode neste sentido ser utilizado como uma estratégia para esta inclusão. Os resultados são apresentados dando destaque ao perfil dos entrevistados; a percepção sobre a formação continuada e sua relação no trabalho com alunos com TEA; as principais barreiras para inclusão dos alunos com TEA; e a percepção do brincar como estratégia para inclusão dos alunos com TEA.

Quanto ao perfil dos entrevistados, observou-se que $92,86 \%$ se autodeclaram do sexo feminino e $7,14 \%$ do sexo masculino. Em relação a faixa etária, 53,57\% dos profissionais estão entre 40 e 50 anos; $25 \%$ entre 30 e 40 anos;14,28\% acima dos 55 anos e 7,14\% entre 20 e 30 anos. Nota-se que 67,85\% dos profissionais estão acima de 40 anos o que pode denotar maior experiência profissional. 
Dentre os participantes, $46,42 \%$ são formados em pedagogia, 17,85\% tem especialização, 17,85\% são formados em Normal Superior, 10,71\% em Graduações em áreas afins e 7,14\% tem licenciatura em Educação Especial. Ainda em relação a formação $71,42 \%$ dos respondentes afirmaram ter realizado cursos de formação continuada em Educação Especial ou Educação Inclusiva e outros $28,58 \%$ não possuem cursos nestas áreas.

Ainda observando o perfil dos respondentes percebe-se que 71,42\% atuam na Regência de Turma, $10,71 \%$ trabalham no Atendimento Educacional Especializado (AEE); 3,57\% como regente de sala de recurso; 7,14\% na supervisão pedagógica e 3,57\% na direção escolar. Estes profissionais atuam nos diversos anos do Ensino Fundamental, sendo 35,71\% no $1^{\circ}$ ano, 7,14\% no $2^{\circ}$ ano, $10,71 \%$ no $3^{\circ}$ ano, $17,85 \%$ no $4^{\circ}$ ano e $28,58 \%$ no $5^{\circ}$ ano o Ensino Fundamental.

Quanto ao perfil dos respondentes percebeu-se então, que estes são em sua maioria, mulheres acima de 40 anos, com graduação em pedagogia e cursos de formação continuada em Educação Especial ou Educação Inclusiva que atuam como regentes de classe, principalmente lecionando no $1^{\circ}$ ano do Ensino Fundamental I.

Em relação à formação para trabalhar com inclusão, na percepção de 75\% dos profissionais entrevistados, o município e a escola investem na formação continuada dos professores em Educação Especial e Inclusiva. Contudo, os outros $25 \%$ dos respondentes afirmaram não perceber este investimento na formação. $\mathrm{O}$ investimento na formação continuada dos profissionais da educação é um ponto importante na mudança de paradigmas que favoreçam a inclusão nas escolas. Rocha (2017) destaca que a formação continuada é a possibilidade de repensar e criar novas propostas de inclusão para as escolas. Alves e Alves (2016) corroboram com esta ideia, destacando que os alunos com TEA surgem como um desafio para os profissionais da educação, incentivando-os ao desenvolvimento de estratégias de ensino, provocando neles um movimento de procura por conhecimento na área.

Em relação ao trabalho com alunos com TEA, 78,58\% dos profissionais respondentes avaliam que saberiam identificálos; $17,85 \%$ das pessoas não sabem responder e os outros 3,58\% afirmam que não conseguiriam identificar um aluno com TEA. Neste aspecto observa-se a importância da formação continuada dos professores, a qual pode contribuir para construção de conhecimento científico e prático para identificar os sinais de uma criança com TEA. Alves e Alves (2016) reforçam esta ideia enfatizando que quanto mais conhecimento na área, maior é a capacidade dos profissionais da educação em identificar e intervir na formação de alunos com TEA. Rocha (2017) dialoga com Alves e Alves (2016) quando salienta que uma escola inclusiva, de todos e todas, depende de adaptações estruturais e pedagógicas de grande e médio porte. Adaptações que favorecem continuamente a formação e aperfeiçoamento dos profissionais da educação para que possam identificar e saber trabalhar com aspectos intrínsecos e peculiares de crianças com TEA. A falta de formação continuada dos profissionais da educação reforça o posicionamento de Ramos e Ribeiro (2018) que sustentam que a deficiência de conhecimento na área interfere diretamente na prática pedagógica do professor.

Dentro dessa mesma perspectiva, foi perguntado aos profissionais se os mesmos já trabalharam ou trabalham com alunos com TEA, sendo que 64\% afirmou que já trabalharam; $21 \%$ dos profissionais trabalham na atualidade com alunos com TEA; $11 \%$ responderam nunca ter trabalhado e $4 \%$ a firmam que nunca trabalharam, mas gostariam de trabalhar.

Quando indagados sobre as barreiras que as crianças com TEA enfrentam em sua inclusão escolar, os respondentes destacaram: a falta de informações dos pais sobre o autismo e suas possibilidades; a falta de uma equipe multidisciplinar para o acompanhamento e desenvolvimento dos alunos no processo de ensino-aprendizagem e ainda, a omissão da família no acampamento da vida escolar. Ramos e Ribeiro (2018) observam que pelo fato do autismo ser considerado somente em 2012 uma deficiência pela lei (Brasil, 2012), até então as diretrizes de trabalho educacional consideravam o aluno com TEA como uma criança neurotípica, sem a necessidade de intervenção de um especialista ou um professor de apoio.

A falta de uma equipe multidisciplinar e especializada nas diversas necessidades educacionais especiais traz prejuízo para aquele aluno que necessita da intervenção e adaptação de atividades e aulas. Isso só é verificado na presença da figura do 
professor de atendimento educacional especializado. Vale ressaltar, ainda, que a falta de informação e orientação da maioria dos pais faz com que eles somente fiquem sabendo das necessidades educacionais dos alunos no momento do contato com a escola.

Em relação a importância do brincar para o desenvolvimento das crianças com TEA, 96\% dos profissionais afirmam que o brincar contribui para o desenvolvimento destas crianças e outras $4 \%$ não percebem esta contribuição. Esses dados demonstram que o brincar é percebido como um grande aliado para a aprendizagem e desenvolvimento das crianças de forma geral, como apontado por quatro dos respondentes (P-01, P-02, PAEE-02 e P-03):

"Através do brincar, as crianças lidam com desafios e possibilidades, que contribuem para o desenvolvimento pleno em todos os aspectos" (P-01).

"Brincando o aluno desenvolve suas habilidades emocional, fisico e motora" (P-02).

"É comprovado cientificamente que brincar ajuda no desenvolvimento das crianças, e muitas brincadeiras ajudam no desenvolvimento do raciocínio lógico" (PAEE-02).

"É certo que o brincar é fundamental para o desenvolvimento de uma criança, uma vez que estimula o progresso de diversas habilidades, como a imaginação, atenção, memória, criatividade, entre outras diversas áreas" (P-03).

Observa-se que os respondentes pontuam o brincar como elemento impulsionador no desenvolvimento global das crianças. Segundo Lameirão (2007) o brincar é uma atividade espontânea da criança, com isso ela pode desenvolver habilidades que ninguém pode ensinar. A partir dessas atividades lúdicas e livres a criança se desenvolve e constrói novas habilidades, com a vivência de desafios apresentados pela brincadeira.

Evidencia-se nos resultados que os respondentes apontam o brincar como fator de desenvolvimento por proporcionar interação e aprendizagem. Podemos observar estas duas categorias nas falas das respondentes P-02, D-01 e PAEE-01.

O desenvolvimento estaria entrelaçado a interação que o brincar proporciona:

"Através da brincadeira a criança explora o mundo e constrói relacionamentos" (P-02).

"Favorece a formação de vínculos afetivos comunicação e compreensão" (D-01).

"Brincando a criança desenvolve sua coordenação motora, a fala e o convívio com outras crianças" (PAEE-01).

A interação com o outro e com o meio, durante o ato do brincar livre, faz com que a criança desenvolva a autonomia, através da comunicabilidade, da imitação, da colaboração com o outro. Pode-se observar que a interação é um fator impulsionador do desenvolvimento por fazer a criança vivenciar experiências de descobertas ligadas tanto ao aspecto motor quanto intelectual e emocional.

Aponta-se também o desenvolvimento sendo alavancado pelas aprendizagens que as crianças realizam quando brincam:

"A brincadeira é um excelente meio de promover a aprendizagem, influenciando diretamente na construção da identidade e da autonomia da criança. Pois através do brincar as crianças desenvolvem capacidades importantes como: o raciocínio, a imaginação, a memória, a atenção e a interação" (PAEE 01).

"Através do brincar a criança aprende de forma lúdica. E através do brincar, o lúdico que a criança desenvolve no processo ensino aprendizagem" (PAEE-02).

"Através da interação com os objetos a criança é capaz de construir a aprendizagem de forma prazerosa" (P-01).

A aprendizagem, quando é desenvolvida com ludicidade e autonomia, cria maneiras e situações que favorecem o desenvolvimento pessoal e social da criança. São situações de imaginação e intervenção lúdica que trazem proveito para uma criança no espaço escola, em especial aquela com necessidades educacionais especiais. Em relação ao brincar como uma 
estratégia para inclusão de alunos com TEA, 79\% das respondentes salientam a importância do brincar ser utilizado como uma estratégia para a inclusão da criança com TEA na escola e 21\% responderam que não é possível considerar o brincar nesta perspectiva.

Pode-se observar nas falas dos $79 \%$ dos respondentes que apontam o brincar como uma estratégia para a inclusão dos alunos com TEA dois motivos para elas fazerem esta afirmação. Os respondentes apontam o brincar como uma atividade que propicia interação (como já haviam pontuado) e ainda afirmam o caráter de respeito a diferença que o ato de brincar traz.

Podemos observar os aspectos da interação nas falas abaixo:

"Porque brincando a criança desenvolve sua coordenação motora fina, grossa. Sua imaginação, sua criatividade, a conviver e compartilhar com outras crianças, a obedecer às regras etc" (PAEE- 01).

"Brincadeiras ajudam na comunicação, compreensão e estimula o aluno. Porque ele vai se sentir incluído, um membro do grupo" (PAEE-02).

"Não há como negar que crianças com TEA apresentam deficiências no contexto da interação social e comunicação, além do mais, possuem padrões de comportamentos repetitivos. É certo que o brincar funciona como um tratamento para os mesmos, uma vez que estimula a socialização e diminui o comportamento repetitivo, por isso é fundamental para o desenvolvimento dessas crianças" (D-01).

Evidencia-se o caráter de respeito as diferenças que o brincar introduz no grupo de crianças:

"Na brincadeira pode envolvê-lo a estar com outro, de maneira sutil, sem forçar. A brincadeira sempre aproxima as crianças, porque é o que elas mais amam fazer. O momento em que os alunos se relacionam, uns aprendendo com os outros. Cada um respeitando as diferenças" (PE-01).

"Sim pois já tive um aluno surdo que tinha TEA e nesta hora tanto ele como os demais alunos gostavam de estar brincando com ele" (D-01).

"Brincadeiras ajudam na comunicação, compreensão e estimula o aluno. Porque ele vai se sentir incluído, um membro do grupo (PAEE-02)".

O brincar tem como sua essência a possiblidade da criança, a partir do ato livre e autônomo, de criar vínculos através da interação e da comunicação, seja com uma outra criança ou através do contato com um adulto. Dentro dessa perspectiva, é importante trazer mecanismos e meios que fazem com que a criança com TEA tenha participação nas atividades lúdicas, incluindo-a para que se sinta parte do processo e possa aprender novas habilidades e também possa ganhar afetivamente com o processo da brincadeira. Diante disso, podemos destacar algumas falas que enfatizam esse caráter intrínseco e peculiar que a participação das crianças com TEA na promoção, organização e desenvolvimento das atividades, que serão desenvolvidas junto com as outras crianças.

"No recreio, incentivo a correr com os coleguinhas, esperar a vez na fila do balanço. Nas aulas de educação física. Sempre fico junto fazendo com toda a turma" (P-01).

“As brincadeiras estimulam a comunicação entre o aluno autista e a pessoa que está por perto" (D-01).

"É notável que crianças com TEA possuem algumas limitações em algumas atividades, no entanto, algumas são ferramentas eficazes no processo de desenvolvimento, tem-se como exemplo tampinhas coloridas (ideais para desenvolver ligeiras percepções em relação ao formato e tamanho de objetos), músicas infantis e danças (estimulando a participação fisica e a imaginação), entre outras que estimule a sua interação no convivio social" (PAEE-02).

"A socialização melhora e muito no brincar para a criança autista" (P-02).

A importância do brincar é expressa na fala de 98\% dos entrevistados, mas somente 79\% deles utilizam dessa estratégia nas aulas e no processo de inclusão. Teles (1997), assim como Damasceno, Leandro e Fantacini (2017) frisam a importância do 
brincar para a leitura do mundo pela criança e a sua exploração, trazendo para ela a possibilidade de se compreender como parte do mundo, em sua historicidade, antes mesmo de haver algum tipo intervenção escolar. Assim, o brincar, na percepção da maior parte dos entrevistados também pode ser utilizado na interação de crianças com TEA na escola.

\section{Conclusão}

No ambiente escolar, é importante os educadores conhecerem as especificidades de cada aluno, se inteirando dos desafios, das barreiras e dos progressos de cada um. A escola inclusiva deixou esta necessidade de atenção individualizada ainda mais premente.

Assim, é necessária uma busca contínua por novos conhecimentos, sendo a formação continuada fundamental para capacitar os professores para responder aos desafios que cada aluno coloca ao mesmo ao processo de ensino-aprendizagem.

Os profissionais da educação da escola estadual do Município de Governador Valadares/MG que participaram do presente estudo afirmaram a importância da educação continuada principalmente em relação a inclusão.

Na percepção destes profissionais o brincar favorece na inclusão de alunos diagnosticados com TEA e se pode ser utilizado como uma estratégia para esta inclusão, principalmente por propiciar o desenvolvimento global das crianças, uma vez que, na visão dos mesmos propicia aprendizagem, interação e respeito a diferença.

Observou-se no estudo que a maioria dos educadores sabem identificar uma criança com TEA, e conhecem suas necessidades educacionais, porém, ainda necessitam de intensificar o diálogo com a família, para que haja conhecimento mútuo dos pontos necessários a serem trabalhados para o maior desenvolvimento e interação dos alunos com TEA.

\section{Referências}

Alencar, D. N. F.; Alves, C. D. N.; Silva, C. O. et al. Educação inclusiva, política educacional e direitos humanos: uma reflexão sobre a legislação brasileira. In: Congresso Nacional De Educação, 2016, Natal. Anais... Natal: Editora Realize.

Almeida, M. T. P. Brincar: uma aprendizagem para a vida. In: Almeida, M. T. P. Brincar, amar e viver. Storbem Gráfica e Editora, 21-72.

Almeida, M. T. P. O jogo simbólico e sua importância no brincar infantil. In: Almeida, M. T. P. Brincar, amar e viver. Storbem Gráfica e Editora, $193-238$.

Alves, M. A. G. \& Alves, M. P. O brincar como intervenção pedagógica nos transtornos do espectro do autismo. Revista Práxis, 8(1), 73-82.

Arruda, G. A. de. \& Dikson, D. Educação inclusiva, legislação e implementação. Reflexão e Ação, 26(2), $214-227$.

Associação Americana de Psiquiatria. DSM-5 Manual diagnóstico e estatístico de transtornos mentais. (5a ed.), Artmed.

Brasil. Constituição da República Federativa do Brasil.

Brasil. Base Nacional Comum Curricular. BNCCMEC.

Brasil. Declaração de Salamanca e linha de ação sobre necessidades educativas especiais. UNESCO.

Brasil. Lei $n^{\circ}$ 9.394, de 20 de dezembro de 1996. Estabelece as Diretrizes e Bases da Educação Nacional.

Brasil. Lei $n^{\circ}$ 12.764, de 27 de dezembro de 2012. Define a Política Nacional de Proteção dos Direitos da Pessoa com Transtorno do Espectro Autista.

Brasil. Diretrizes Nacionais para a Educação Especial na Educação Básica. SEESP.

Cipriano, M. S. \& Almeida, M. T. P. de. O brincar como intervenção no Transtorno do Espectro do Autismo. Extensão em Ação, 2(11), 78-91.

Cunha, N. H. S. Brinquedoteca: um mergulho no brincar. (4a ed.), Aquariana, 2007.

Daguano, L. Q. \& Fantacini, R. A. F. O lúdico no universo autista. Linguagem Acadêmica, 1(2), 109-122.

Damasceno, B. C. E.; Leandro, V. S. B. \& FantacinI, R. A. F. A importância do brincar para o desenvolvimento da criança com Síndrome Down. Research, Society and Development, 4(2), 142-152, 2017.

Danton, G. Metodologia Científica. Virtual Books.

Fam, A. E. O.; Reis, S. P. \& Silva, J. R. Inclusão educacional de autistas em escolas militares de Minas Gerais. Educação Pública, 20(5).

Favoretto, N. C. \& Lamônica, D. A. Conhecimentos e necessidades dos professores em relação aos transtornos do espectro autístico. Revista Brasileira de Educação Especial, 20(1), 103-116, 2014. 
Research, Society and Development, v. 10, n. 6, e49010615912, 2021

(CC BY 4.0) | ISSN 2525-3409 | DOI: http://dx.doi.org/10.33448/rsd-v10i6.15912

Freire, P. Pedagogia do Oprimido. (62a ed.), Paz e Terra, 2016.

Freire, P. Pedagogia da Autonomia: saberes necessários à prática educativa. (63a ed.), Paz e Terra.

Gerhardt, T. E. \& Silveira, D. T. Métodos de Pesquisa. Editora da UFRGS.

GIL, A. C. Como elaborar projetos de pesquisa. (4a ed.), Atlas.

Lameirão, L. H. T. Criança brincando! Quem educa? João de Barro.

Mantoam, M. T. E. O direito à diferença nas escolas: questões sobre a inclusão escolar de pessoas com e sem deficiências. Revista Educação Especial, 1(23), $51-56,2004$.

Mantoam, M. T. E. Inclusão escolar: o que é? por quê? como fazer? Moderna.

Martins, B. V. B. \& Alves, S. L. C. O brincar e as NEE's: necessidades educacionais especiais. Trajetória Multicursos, 10(2), 65-80, 2018.

Mendes, E. G. Perspectivas para a construção da escola inclusiva no Brasil. In: Palhares, M. S. \& Marins, S. C. Escola Inclusiva. São Carlos: EdUFSCar, 6185 .

Miranda, A. A. B. Educação especial no Brasil: desenvolvimento histórico. Cadernos de História da Educação, 7(1), 29-44.

Raiça, D.; Prioste, C. \& Machado, M. L. G. Dez questões sobre a educação inclusiva da pessoa com deficiência mental. Avercamp.

Ramos, A. R. \& Ribeiro, F. L. S. A inclusão de crianças autistas em meio ao brincar: o que pensam as professoras. In: V CONGRESSO NACIONAL DE EDUCAÇÃO, 2018, Olinda. Anais... Olinda: UFPE.

Rocha, A. B. O. O papel do professor na educação inclusiva. Ensaios Pedagógicos, 7(2), 21-29.

Santana, M. L. S.; Purificação, M. M.; Teperino, A. P. P. et al. O brincar como elemento de inclusão escolar de crianças caracterizadas com Transtorno do Espectro Autista (TEA). Interfaces da Educação, 7(19), 48-65.

Santhiago, D. S. \& Colonetti, C. L. A relação dos professores regentes e professores do atendimento educacional especializado - AEE nos anos iniciais do ensino fundamental no município de Criciúma. Saberes Pedagógicos, 1(1), 42-61.

Sawaia, B. B. As artimanhas da exclusão: análise psicossocial e ética da desigualdade social. (3a ed.), Vozes.

Silva, A. D. P.; Dias, G. R.; Martins, M. M. et al. Autismo: a utilização do brincar como forma de interação social. In: XIII Jornada De Ensino, Pesquisa E Extensão - JEPEX, 2013. Anais... Recife: UFRPE.

Teles, M. L. S. Socorro! É proibido brincar. Vozes.

Vigotsky, L. S. A formação social da mente. Martins Fontes. 